\title{
Surfaces
}

\section{The Predicament of Culture At Room Temperature}

\section{Jennifer Allen}

Volume 6, 1996

LES ÉCONOMIES DISCURSIVES DU SAVOIR ET DE LA CULTURE DANS

LE SILLAGE DE L'OEUVRE DE BILL READINGS

THE DISCURSIVE ECONOMIES OF KNOWLEDGE AND CULTURE,

WITH CONSTANT REFERENCE TO THE WORK OF BILL READINGS

URI : https://id.erudit.org/iderudit/1064853ar

DOI : https://doi.org/10.7202/1064853ar

Aller au sommaire du numéro

Éditeur(s)

Les Presses de l’Université de Montréal

ISSN

1188-2492 (imprimé)

1200-5320 (numérique)

Découvrir la revue

Citer cet article

Allen, J. (1996). The Predicament of Culture At Room Temperature. Surfaces, 6. https://doi.org/10.7202/1064853ar d'utilisation que vous pouvez consulter en ligne. 


\section{The Predicament of Culture At Room Temperature}

Jennifer Allen

Université de Montréal

Surfaces Vol. VI. 208 (v.10A - 13/12/1996) - ISSN: 1188-2492

Copyright for texts published in Surfaces remains the property of authors. However, any further publication should be accompanied by an acknowledgement of Surfaces as the place of initial publication.

Culture is a deeply compromised idea I cannot yet do without. James Clifford

\section{I.}

At Rethinking Culture[ $\underline{\mathbf{1}}$ ], a conference that was held at the Université de Montréal in early 1992, Ron Schleifer gave a talk about the institutionalization of Cultural Studies in the United States. At one point, as an aside, he described his own attempt to create a Cultural Studies programme with colleagues in the English Department at Oklahoma University. Things were going along just fine, it seems, until a complaint was issued from the Anthropology Department. The anthropologists there contended that the English Department had no right to claim culture as an object of study. Within the university, they argued, culture had been, and should remain, the domain of anthropologists. On what grounds, the anthropologists asked, could the English Department claim to study culture, when the history and 
methodology for studying culture had been developed within the field of anthropology?

I don't know the sequel to Ron Schleifer's story-and I am not sure if he and his colleagues succeeded in getting their Cultural Studies programme out of its predicament-, but this sequence of events suggests what is at stake in the institutionalization of Cultural Studies. The dispute here involves disciplining culture. And the conflict is not so much about the content of culture, but rather about who has the right to designate culture as an object of study. Given that cultural difference provides the grounds for the field of anthropology, I doubt that the anthropologists at Oklahoma, or any where else for that matter, would deny that the English Department is both the site and the expression of a particular culture, and this long before its foray into Cultural Studies. The problem for the anthropologists is that the English Department should be disseminating culture and not studying it. In short, if one follows the logic of the complaint issued by the Anthropology Department, the professors and students in English should remain practitioners of culture, and not practitioners of Cultural Studies.

It should come as no surprise to those who identify themselves as practitioners of Cultural Studies that their proposed field of study can quickly and quite effortlessly become a battleground between a Department of English and a Department of Anthropology. Although Cultural Studies has a diverse history in the English-speaking academic community, the general project of Cultural Studies implies a critique of both humanist and anthropological definitions of culture. In the Routledge Cultural Studies reader, for example, editors Larry Grossberg, Cary Nelson, and Paula Treichler define Cultural Studies as an interdisciplinary, transdisciplinary, and sometimes counterdisciplinary field that operates in the tension between its tendencies to embrace both a broad, anthropological and a more narrowly humanistic conception of culture (4). By attempting to embrace both the anthropological and the humanistic conceptions of culture, Cultural Studies brings to the fore a certain contradiction with respect to the differentiating function of culture operative within the university. This contradiction can be put, although somewhat crudely, as follows. Historically, the English Department has said: culture is here; we have culture; and that is what we are going to give you. While over in the Anthropology Department they say: culture is out there; they have culture; and we will teach you how to see it. 
Two distinctions are at work here that give rise to culture within the institution. A class difference underlies traditional literary studies, which historically have disseminated high culture and operated in opposition to working class culture and popular culture. Geographical differences ground traditional anthropological studies, which historically have constructed fields of study outside of the self-identified Western culture. These differences may be linked to a temporal hegemony, where high-brow culture and Western culture are understood as being more advanced than their respective other cultures. Cultural Studies unmasks these differences as expressions proper to elitism and imperialism; it thus demonstrates the complicity of the university's configuration of culture with class exploitation and colonialization. And yet it does so in the name of culture, albeit a kinder and gentler culture. Instead of doing away with the notion of culture, Cultural Studies proposes an ever-increasing democratization of culture, whereby culture may be found anywhere and approached through a whole range of methodologies.

As such, Cultural Studies must occupy a kind of no-man's land within the institution if it is to avoid creating a new set of cultural differences, and this is perhaps the tension that Grossberg, Nelson, and Treichler associate with the inter-, trans-, and sometimes counter-discipline of Cultural Studies. The predicament of Cultural Studies, in short, is to differentiate its field of study from traditional literary and anthropological studies without instituting a new set of cultural differences that would undermine its original critical project. Cultural Studies must maintain the possibility of cultural difference without giving a definitive content to that difference. Reading Into Cultural Studies, a book that offers critical readings of some early, key texts in Cultural Studies, provides an example of how the critical capacity of Cultural Studies can be seriously compromised when a definitive content is given to culture. In their introductory article, editors Martin Barker and Anne Beezer show a marked preference for the field of culture that arises through class differences; in their eyes, the culture in Cultural Studies should be understood exclusively in terms of class. To illustrate their point, Barker and Beezer turn to Angela McRobbie's reassessment of her own 1991 study Feminism and Youth Culture, which was oriented by a class paradigm. The editors criticize McRobbie for stating that her study would have benefited from a consideration of gender over class differences. In the name of Cultural Studies, 
both claims set up the kind of hierarchy that the field seeks to dismantle. Once again, the predicament of Cultural Studies is to avoid instituting a new set of cultural differences that would compromise its original critical project. A kinder and gentler culture means a culture without a definitive content. Culture at room temperature is not, then, an allusion to the entropy of disappearing cultural difference but rather to the attempt to recognize contemporaneous cultural difference in one given field within the institution.

\section{II.}

At the risk of becoming an anthro-apologist, I would like to return to the conflict with the anthropologists to understand the nature of the tension that exists between anthropology and Cultural Studies-from the anthropologist's point of view. How does the practitioner of Cultural Studies appear in the eyes of the anthropologist? Initially, one must admit that things don't look good for the Cultural Studies person who happens to venture into the Anthropology Department, given that Cultural Studies refuses to disclose its object of study, methodologies, or canonical texts and, in the same instance, insists that Cultural Studies is not just anything, (a move that might be akin to presenting oneself at the border, insisting on one's identity, and then refusing to show a passport). Although the rise of anthropology has been linked to colonial expansion, there has been and continues to be an on-going dialogue among anthropologists about how to understand cultural difference. An important part of this dialogue has been a critique and revision of the anthropological gazealthough sometimes just a slight refocusing. I am not claiming that anthropology is somehow more equiped than Cultural Studies to study culture because of its institutional history. Rather, I would like to suggest that there might be something to be gained from the disputes among anthropologists as well as the transformations within this field.

In order to understand the differences between the anthropologist and the practitioner of Cultural Studies again, from the anthropologist's point of view -, I'd like to refer to The Accidental Tourist, the novel by Anne Tyler, which was made into a film of the same title. The story centers on Macon Leary, a man who writes travel guides for American business people who find 
themselves in foreign countries. Macon hates to travel, as do his readers. His guides carry an image of an armchair with wings, the Accidental Tourist logo. Macon travels in order to record traces of America-that is, traces of the same-elsewhere. Tyler writes, He covered only the cities in these guides, for people taking business trips flew into cities and out again and didn't see the countryside at all. They didn't see the cities, for that matter. Their concern was how to pretend they had never left home. What hotels in Madrid boasted kingsized Beautyrest mattresses? What restaurants in Tokyo offered Sweet'n'Low? Did Amsterdam have a McDonald's? Did Mexico City have a Taco Bell? Did any place in Rome serve Chef Boyardee ravioli? Other travelers hoped to discover distinctive local wines; Macon's readers searched for pasteurized and homogenized milk (12).

Sounds like an anthropologist's nightmare. Of course, the anthropologist is situated on the opposite end of the spectrum. Where the Accidental Tourist looks for traces of the same while travelling, the anthropologist travels in order to find the differences that ground her field of study. Fieldwork is a necessary part of her academic training and institutional identity. The anthropologist wants at all costs to avoid feeling at home elsewhere. She thus ignores the signs that she may recognize and records traces of cultural difference that she finds in the field. The anthropologist's trip may be filled with accidents, but it is never accidental. In contrast to the Accidental Tourist, the anthropologist is obliged to travel in order to become what might be called an Intentional Tourist. She travels in and out of areas in search of cultural difference.

The practitioner of Cultural Studies appears somewhat parallel to the anthropologist, although she does not need to travel in order to find the differences that ground her field of studies. Culture, after all, may be found anywhere. It is always possible to find oneself in the midst of Cultural Studies fieldwork since the culture of Cultural Studies is always changing. In order to do research, the practitioner of Cultural Studies must avoid at all costs feeling at home-at home. In other words, she looks for difference in the same. And in order to find the traces of cultural difference that ground her field of studies, she often effects a displacement without travelling. Heading off to the field, perhaps even unknowingly, without a fixed idea of her object of study, her methodology, or even what the field will look like, the practitioner of Cultural Studies is a sort of Accidental Anthropologist. She stays put and finds cultural 
difference. Given the challenge inherent to fieldwork, as well as its history, one can understand why an Anthropology Department might feel somewhat vexed by a Cultural Studies programme proposed by the English Department.

\section{III.}

The title of this paper is of course also a reference to James Clifford's book The Predicament of Culture. In order to understand the encounter between the fields of anthropology and of Cultural Studies, I would like to consider Clifford's contribution to the Grossberg, Nelson, and Treichler Cultural Studies reader, an article entitled Traveling Cultures. Initially, the contribution appears to create a rather strange alliance. A historian, Clifford writes on the history of anthropology; his work has been associated with the turn towards a critical understanding (and rewriting) of ethnography, a project undertaken primarily within anthropology and with reference to historical fieldwork of the Intentional Tourist types. How is it that Clifford is all of a sudden a Cultural Studies person? What is the nature of his contribution to the Cultural Studies anthology? Is it ethnography or Cultural Studies? And, of course, the burning question is: how can one tell the difference?

I would argue that there is a certain conjuncture between Clifford's critical rewriting of ethnography and the project of Cultural Studies. But I would add that Clifford's contribution to the field of Cultural Studies remains distinctly and even stubbornly within the field of anthropology. It might even be understood as a uniquely anthropological response to the challenge posed by Cultural Studies to the anthropological conception of culture. The title of the article, Traveling Cultures, is not, then, a reference to the displacement and circulation of culture that is currently taking place within the institution. Rather, Traveling Cultures implies a recognition of the displacement and circulation of the traditional field of culture-and fieldwork-in a global economy. Cultural differences have not disappeared; they are simply on the move; and they coexist in a contamination that does not erase their differences.

In Traveling Cultures, Clifford demonstrates not only how travel recognizes a creative, almost democratic, 
contamination of cultures (informers, just like anthropologists, are on the move). He makes a case for travel as a new field of research, albeit a moving field, for anthropologists and notes the danger of continuing to construe ethnography as field work, which localizes or gives a locale to cultural difference based on geographical distance. According to Clifford, Localizations of the anthropologist's object of study in terms of a field tend to marginalize or erase several blurred boundary areas, historical realities that slip out of the ethnographic frame (99). Clifford then offers a list of the elements that have been traditionally erased by anthropologists in their writing of cultural difference: the means of transport (the boat, land rover, or mission airplane); the capital city or the national context of a study; the anthropologist's home university; and, finally, the sites and relations of translation (99-100).

Clifford's focus on travel articulates an important critique of the traditional mise en scène of anthropological studies, a critique that is in line with Cultural Studies' unmasking of the geographical differences that give rise to culture in anthropology. As Clifford makes clear, the anthropologist does not usually write about her trip to and from the field. A Intentional Tourist type, she must avoid all traces of the same in order to give rise to the cultural differences she seeks out through displacement. The erasure of displacement permits the translation of geographical distance into temporal difference, a translation that places anthropology's other culture in the past and its own activities firmly in the present. As Johannes Fabian has shown in Time and the Other, in anthropology, geographical displacements become a temporal (and historical) ones whereby cultural differences are explained through the speeds of communities relative to the West. Fabian relates that, historically, anthropologists were called time travellers; the cultural differences that unfolded for the modern European could not be contained in the present; Europeans placed the cultures they discovered in their own past and situated themselves in the present. Historically, the erasure of all traces of travel has served to affirm the authority of anthropologists to speak about other cultures as part of a dead or dying past (and to ignore the cultural specificity of their own activity). Clifford's focus on travel undoes the construction of cultural difference in time (and history); he negates authority in anthropology that is based on the West's supposed rapidity. In effect, Clifford's critical project for anthropology involves an epistemological displacement: anthropologists stop time travelling and start making geographical trips. 
By focusing on travel, however, Clifford also establishes a great distance between his own critical project and that of Cultural Studies. The difference between the anthropologist and the practitioner of Cultural Studies is, of course, the trip. The practitioner of Cultural Studies does not need to travel since, for her, culture may be found anywhere. Clifford seems to agree with this vision of culture except he sees a circulation of cultures-travelling cultures-and not the omnipresence of culture. Practitioners of Cultural Studies, at least those who come from literary studies, $d o$ travel-but only for conferences. Travel is not part of their training; to the anthropologist, they remain, as it were, Accidental Anthropologists. In proposing travel as the site of future ethnographies, Clifford guarantees the continuity of a uniquely anthropological critical project, one that leaves Cultural Studies in the dust.

Faced with the challenge of Cultural Studies, namely its critique of the geographical differences that give rise to culture for anthropology, the anthropologist can only write about her trips; travel is the only way she can distinguish her research from Cultural Studies. The future of Cultural Studies is culture whereas the future of anthropology is travel writing. But the trip Clifford proposes for future anthropological studies has no end, no beginning, and no destination. Once the anthropologist of the future stops moving, she risks becoming a practitioner of Cultural Studies. It is only in perpetual motion that the anthropologist can give rise to truly anthropological studies. Faced with the possibility of the globalization of the disciplines, Clifford responds with a mercantile economy of knowledge, where what goes out always comes back as anthropology. Moreover, with his focus on travel, Clifford seems to underscore inequalities between anthropologists and informers, which he originally hoped to dismantle, because, as bell hooks notes in her response to Clifford's paper, travel is the most privileged means of displacement. Travel stands in stark contrast to the displacements associated with deportation, war, emigration, slavery, exil, and forced relocation. Cultures may very well be on the move towards the end of the 20th century, but it is surely not due to a more egalitarian distribution of wealth, whereby more people can finally afford the luxury of taking a trip. 


\section{IV.}

I would like to extend the economic metaphor used above, just once more. If Clifford proposes a mercantile economy of knowledge, then Cultural Studies embodies the freemarket model, where the barriers formerly surrounding the notion of culture in the university have finally been lifted to allow for the free flow of culture, irrespective of its content. But, as Bill Readings has argued, the end of cultural hierarchies operative within the university should not be equated with the longawaited emancipation of the people who have been oppressed by them. For Readings, the democratization of culture that Cultural Studies celebrates should make one wonder if the stakes in the game have not changed. Indeed, the end of cultural hierarchies-whether based in class or geography-may simply mean that culture is no longer a viable tool in class exploitation and colonization. In other words, the liberation of culture has come too late and carries no punch. There is also the danger that the epistemological shifts set into motion by Cultural Studies reflect a new organization of knowledge for new relations of power. If the university's configuration of culture has been complicit with class oppression and colonization in the past, then what is there to guarantee that the current configuration-be it travelling culture or culture without a predetermined content-is not simply legitimating new forms of domination?

Whatever the historical shortcomings of Cultural Studies, I think it is impossible to reverse its critical claims. In the wake of Cultural Studies, there is simply no going back to the heyday of culture, the time when we knew what culture was (and was not). At the same time, I would suggest a backward glance as a kind of strategy in the face of the dissolution of cultural hierarchies within the institution. What is striking about Cultural Studies is the need to create an institutional space, and, in Clifford's particular response to the field, the need to protect one. In both cases, the critical moment is quickly overcome in order to make way for the production of a knowledge that has not only a clear conscious but also a clear institutional identity, one that is distinct from other fields, albeit in ways we cannot fully grasp. But institutional identity always involves a relationship to power. While Cultural Studies has so far succeeded, with a few exceptions, in avoiding giving a definitive content to culture, there will be a point within its institutional history when members of the field will 
have to reject a study because, quite simply, it is not Cultural Studies. In the same manner, Clifford's project for anthropologists will eventually come across a work that is only travel writing and thus cannot carry the name of anthropology. If both wish to avoid being the future bearers of a new cultural hierarchy, then it may be wise to take their critical insights, not as the occasion to create a new department or programme or project, but as a form of memory within the institution. My suggestion of a backward glance is a way of accepting the critical claims of Cultural Studies, but with understanding that there will never be a critical movement that somehow purifies the university of all its past wrongs and protects it against future errors. Dreams of these kinds of utopias landed the institution in trouble in the first place. If Cultural Studies teaches us anything, it is that the institution alone in no way guarantees the ethical soundness of knowledge produced under its auspices.

Instead of forging ahead with new and improved ideas about culture, I would suggest the somewhat less glamourous project of picking through the epistemological waste left in the wake of the critique of culture. I think that anthropology deserves a return to the problematics of fieldwork (here, I disagree with Clifford). The necessity of fieldwork demonstrates the inadequacy of the epistemological model; if you know what culture is, then there is no need to go to the field. Moreover, fieldwork does not have the same status of an experiment; it is not used to verify a hypothesis, but to search for something that will come to be understood under the sign of cultural difference. In this way, anthropology continually replays the split between the subject of knowledge and the subject of experience, which Giorgio Agamben has identified at the heart of philosophical modernity. The necessity of fieldwork allows one to see this split as a continual source of trauma or anxiety, which every anthropologist must overcome by writing (no small wonder that a $\mathrm{PhD}$ in anthropology takes longer to complete than in other fields). Instead of focusing on the successful results of fieldwork, it would be interesting to look at the process of translation that occurs when experience is transformed into knowledge. The anthropologist's trip may be a worthy topic, but I would prefer to read about the anthropologist's failures, which generally do not make it to publication. I remember an anthropologist telling me how one of his subjects ramsacked his house, tried to set it on fire and in the process destroyed all of his notes; the two subsequently got into a fist fight, then got drunk and finally decided to be friends, whereupon 
the project was abandoned. Another anthropologist related how, after years of studying his field, he finally made it his destination, only to realize shortly after arriving that he could not stand to live there, and so he promptly returned home. Why are these not anthropological studies? Probably because the experiences they relate cannot readily be translated into knowledge; they remain anecdotes or personal testimonies. While they certainly attest to the existence of cultural difference, they somehow fail to make the transition into anthropology's notion of culture. What must be taken away (or added) in order to make them anthropology?

In terms of literary studies, from where Cultural Studies generally seem to have originated, I would suggest following Clifford's line of inquiry. The field of literary studies is desperately in need of a critique of the imperialism that underlies its practises, in particular, in the area of language acquisition. Although there has been an incredible amount of work done at the level of language in texts, especially through deconstruction, there is little inquiry into the literary critic's relation to language. Language acquisition has generally been treated as a chore-and language, as an instrument that allows access to selected national-literary or minorliterary destinations. Like the anthropologist's trip, the process of language acquisition has been erased in order to effect an objectivity in the literary critic and a timeless solidity in the literary object. The native speaker is often called upon by the literary critic to play a role similar to that of the anthropologist's informant, offering a correct pronunciation or helping to interpret a complex passage. In order to understand the role that language acquisition has played in sustaining a notion of cultural difference within the university, one could apply Clifford's set of questions about the anthropologist's trip to the literary critic's language. Clifford's means of transport becomes a question about the conditions under which a language has been learned; his capital city or national context would reflect a sensitivity with respect to dialects, accents and other markers within language; a reflection on the home university would raise questions about the status of foreign languages spoken in literary departments as well as the relation between language and literature professors; and, finally, Clifford's sites and relations of translation would not be a call for more translation theory but a question about what is considered to be foreign in a language and its speaker. Given the importance of critiquing nation-state formations of literatures in the 1980s, especially in the light of postcolonial, minor and emergent literatures, the 
literary critic's relation to language becomes an important consideration because the critic develops a sense of belonging and identity through a language that is not necessarily a result of nationality or geography. Alice Yaeger Kaplan's French Lessons is an excellent example here. A native American English speaker, Kaplan shows how her decision to learn French is linked to the death of her father. Consequently, when she finds herself in the United States around the anniversary of her father's death, she speaks French in order to effect a distanciation. And, if one compares the literary critic's languages to the anthropologist's trips, then obviously bell hooks's charge of imperialism applies; in the university, learning about cultural difference through language is generally the result of choice and priviledge.

Finally, it will be remembered that a predicament is defined as the character, status, or classification assigned by a predication, in other words a category. But a predicament is also defined as a condition or state, especially a difficult, perplexing, or trying situation. If culture is to become a source of critical thinking, it must be approached as a complex and ethically challenging situation, and not as a label that remains indifferent to what it describes. Getting out of predicament means escaping the incommensurability of what we perceive under the sign of cultural difference. To return to the beginning of this text, to Ron Schleifer's attempt to establish a Cultural Studies programme at Oklahoma University, getting his programme out of its predicament means ending a dialogue, however volatile, about the meaning of culture in anthropology and in literary studies. Given the political orientation of Cultural Studies, it seems that ending such a dialogue would not be in its best interests. In a similar manner, creating a Cultural Studies Department in every university would remove the people who do Cultural Studies from the very situations where their critique of cultural hierarchies would be most effective. If the critique of Cultural Studies is to be a memory, of where the university has gone wrong with culture and where it cannot return, then it seems such an act of memory would be more effective in places where it has already been forgotten or not even thought. 


\section{Bibliography}

Agamben, Giorgio. Infanzia e storia. Distruzione dell'esperienza e origine della storia. Turin: Giulio Einaudi editore, 1978.

Barker, Martin, and Anne Beezer, editors. Reading Into Cultural Studies. London; New York: Routledge, 1992.

Clifford, James. The Predicament of Culture: TwentiethCentury Ethnography, Literature, and Art. Cambridge, Mass.: Harvard University Press, 1988.

Fabian, Johannes. Time and the Other: How Anthropology Makes Its Object. New York: Columbia University Press, 1983.

Grossberg, Lawrence, and Cary Nelson, Paula Treichler, editors. Cultural Studies. New York: Routledge, 1992.

Kaplan, Alice Yaeger. French Lessons: A Memoir. Chicago: University of Chicago Press, 1993, 1994.

McRobbie, Angela. Feminism and Youth Culture: From 'Jackie' to 'Just Seventeen'. Houndmills, Basingstoke, Hampshire: Macmillan, 1991.

Readings, Bill. Beyond Culture. The Posthistorical University. Cambridge, Mass.: Harvard University Press, forthcoming spring 1996.

Tyler, Anne. The Accidental Tourist. Markham, Ont.: Penguin Books Canada, 1985.

\section{NOTES}

1. This paper, originally presented at the Cultural Studies in Canada conference at the University of Toronto in May 1994, benefited greatly from the arguments presented in an early draft of Bill Readings's book, Beyond Culture: The Posthistorical University, in particular, from the chapter on Cultural Studies.

Accueil Surfaces | Table des matières | Recherche $\underline{\text { Surfaces Home Page | Table of Contents | Search }}$ 